\title{
Tymianek - roślina o wielu zastosowaniach
}

\section{Thyme - multiple use plant}

\author{
MAJA AMBROZIAK ${ }^{1}$, MAŁGORZATA STANOWSKA ${ }^{1}$, KALINA SIKORSKA- \\ ZIMNY2,3
}
${ }^{1}$ Studenci specjalizacji Zioła i żywność funkcjonalna w profilaktyce i terapii, na kierunku Dietetyka, Instytut Nauk o Zdrowiu, Państwowa Uczelnia im. Stefana Batorego. Koło Dietetyków PUSB.
2 Instytut Nauk o Zdrowiu, Państwowa Uczelnia im. Stefana Batorego, Skierniewice.
3 Pracownia Przechowalnictwa i Fizjologii Pozbiorczej Owoców i Warzyw. Instytut Ogrodnictwa, Skierniewice.

DOI: http://dx.doi.org/10.21784/lwP.2020.006

ISSN: 2451-1846

\section{Streszczenie:}

Wstęp. Tymianek jest znany w Polsce od stuleci, początkowo sprowadzany, później uprawiany i ceniony za walory kulinarne, jak i lecznicze. Obecnie jest rośliną powszechnie występującą na terenie Polski. Najczęściej jest stosowany w kuchni, należy jednak pamiętać, iż występuje w składzie wielu preparatów leczniczych. Spotykany w kosmetykach, stosowany w aromaterapii jak i kompozycjach kwiatowych, roślinnych.

Przegląd. Tymianek $\mathrm{z}$ uwagi na obfitość związków o działaniu przeciwdrobnoustrojowym, antyoksydacyjnym, był stosowany przy chorobach dróg oddechowych, działając przeciwzapalnie i wykrztuśnie. Wspomaga funkcjonowanie układu trawiennego (przy problemach żołądkowych, jelitowych, wątrobowych). Intensywny zapach tymianku znalazł zastosowanie $\mathrm{w}$ aromaterapii, jak i wielu kosmetykach jak pasty, kremy czy płyny i sole do kąpieli.

Podsumowanie. Z uwagi na cenne walory tymianek jest coraz częściej postrzegany jako składnik nie tylko nadający zapach, ale i korzystnie działający na produkt. Jego szerokie spektrum właściwości znajduje coraz 
szersze zastosowane w naturalnych preparatach i nowoczesnych produktach spożywczych i kosmetycznych.

Słowa kluczowe: tymianek, właściwości lecznicze i kulinarne, zastosowanie

\section{Summary:}

Introduction. Thyme has been known in Poland for centuries, initially imported, later cultivated and appreciated for its culinary and medicinal values. Currently, it is a common plant in polish region. It is most often used in the kitchen, but it should be remembered that it is included in many medicinal preparations. Found in cosmetics, used in aromatherapy as well as in floral compositions.

Overview. Thyme, due to the abundance of compounds with antimicrobial and antioxidant activity, was used in respiratory diseases, anti-inflammatory and expectorant. It is supporting the functioning of the digestive system (for stomach, intestinal and liver problems). The intense aroma of thyme has been used in aromatherapy and in many cosmetics, such as pastes, creams, lotions and bath salts.

Conclusions. Due to its valuable qualities, thyme is more and more often perceived as an ingredient that not only gives flavor, but also has a beneficial effect on the product. Its wide spectrum of properties causes its increasingly used in natural and modern food and cosmetic products.

Key words: thyme, medicinal and culinary properties, usage

\section{Wstęp}

Tymianek właściwy (Thymus vulgaris L.) znany również jako: tymianek, tymianek pospolity, ogrodowy, prawdziwy, macierzanka tymianek lub tymian należy do rodziny jasnotowatych. Jest to gałęzisty, ciemnozielony półkrzew, wyrastającym do wysokości 25-40 cm. Prawdopodobnie wywodzi się z rejonów Morza Śródziemnego, rośnie dziko w Maroku, Grecji, Turcji, Włoszech i Hiszpanii 


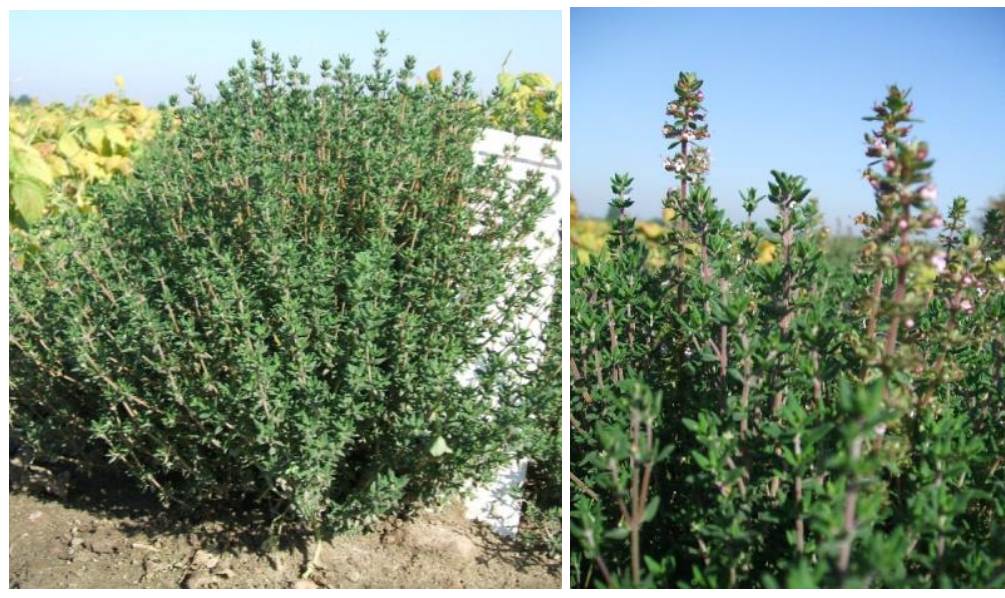

Ryc. 1. Tymianek pospolity (autor dr A. Stępowska).

\section{Omówienie}

Pierwsze opisy tymianku i jego wykorzystania w lecznictwie można znaleźć w „papirusie Ebersa” liczącym ponad 3500 lat. Również na terenie Mezopotamii, w odkopanych glinianych tabliczkach widnieją informacje o leczniczym wykorzystaniu tymianku [1].

W starożytnym Egipcie tymianek był rośliną wykorzystywaną w rytuałach religijnych - do kadzideł i przy mumifikacji zwłok. W starożytnej Grecji Pedanios Dioskorides z Anazarbos (lekarz, farmakolog i botanik), polecał miodowe odwary $\mathrm{z}$ tymianku na choroby płuc [2]. Ziele było polecane również dla kobiet ciężarnych jako środek „ułatwiające zejście łożyska” [1]. Z kolei okłady tymiankowe leczyły choroby weneryczne i "bolączki twarde" (prawdopodobnie chodziło o choroby nowotworowe) [3]. Spożywanie rośliny miało natomiast korzystnie wpływać na wzrok. W starożytnym Rzymie tymiankowi były przypisywane właściwości leczenia: padaczki, rwy kulszowej, kaszlu, a Pliniusz (pisarz rzymski) 
zalecał stosowanie tymianku na szkorbut. Należy jednak dodać, iż starożytni Rzymianie widzieli wtymianku przede wszystkim roślinę kulinarną. W pracy Apiciusa Caeliusa „Decem libri cui dicuntur de re coquinaria...", znajduje się ponad 20 przepisów wykorzystania tymianku w kuchni $[1,4]$.

W starożytnej Grecji tymianek właściwy, zaraz po mięcie czy kwiecie róży wchodził w skład napojów chłodzących. Z kolei miód tymiankowy był uznawany za jeden z najcenniejszych [5].

W XVI wieku we Francji, wino tymiankowe uznawano za uniwersalny lek na choroby głowy, piersi, płuc, żołądka, wątroby, przewodu pokarmowego, śledziony i nerek [1].

Dzięki swoim walorom półkrzew tymianku został spopularyzowany i uprawiany w całej Europie. Do Ameryki przypłynął wraz z nowymi osadnikami [6].

$\mathrm{Na}$ świecie pod względem wielkości powierzchni upraw dominują Chiny, Indie i Egipt. Polska jest największym producentem ziół w Unii Europejskiej. Nasze zioła są jednak cenione z uwagi na wysoką jakość surowca [7]. Ogólnie około 80\% polskiego surowca zielarskiego trafia na rynek europejski [8].

\section{Pozyskiwanie ziela}

Do celów technologicznych prowadzi się dwukrotny zbiór w sezonie wegetacyjnym, zbierając górne części pędów zielnych w pełni kwitnienia. Zbiór powinien obywać się w czasie słonecznej i bezdeszczowej pogody, co pozwala zebrać rośliny obfitujące w największą ilość olejków eterycznych [9].

Z uwagi na różnice klimatyczne na terenie Polski (częstsze i chłodniejsze dni na wschodzie kraju w stosunku do zachodniej części), we wschodnich rejonach plantacje tymianku są zakładane corocznie. W pozostałych częściach Polski zakładane są na 2-3 lata. 
W pierwszym roku po założeniu plantacji zbiór następuje w sierpniu. W kolejnych latach: pierwszy zbiór - przed kwitnieniem, a ostatni nie później niż na początku września [10]. Od czerwca do września, do celów leczniczych zbiera się zakwitające, szczytowe, niezdrewniałe części pędów tymianku. Pierwszy pokos wykonuje się na wysokość $5 \mathrm{~cm}$, kolejne $10 \mathrm{~cm}$ od ziemi (powyżej zdrewniałych pędów) [11].

Zebrane rośliny, luźno ułożone, suszy się w temperaturze $35^{\circ} \mathrm{C}$ (w warunkach domowych często zawieszone w pęczki). Tymianek suszony $\mathrm{w}$ tej temperaturze dobrze zachowuje zieloną barwę [12]. Stopień zachowania barwy produktu uzależniony jest od metody oraz parametrów suszenia. Obniżenie temperatury lub skrócenie czasu procesu ogranicza straty barwników chlorofilowych wywołanych uszkodzeniami termicznymi, podczas których dochodzi do rozerwania kompleksu chlorofili z białkami [13].

\section{Zastosowanie}

Tymianek swoje zastosowanie znalazł przede wszystkim w kuchni i lecznictwie, ale również w kosmetologii i dekoratorstwie. W kuchni zioło to jest stosowane z uwagi na mocny, wyrazisty zapach oraz gorycz, która harmonizuje z daniami mięsnymi [14].

W XVIII w., w Polskiej kuchni tymianek szczególnie był polecany w połączeniu z innymi ziołami jak lebiodka, goździki, gałka muszkatołowa oraz liście laurowe. Takie zastosowanie tymianku opisuje w książce „Kucharz doskonały” (z roku 1786) Wielądko [15]. W dzisiejszej gastronomii tymianku używa się do przyprawiania ryb, gulaszy i paprykarzy, dań z grilla [16]. Stosuje się go w wielu marynatach oraz $\mathrm{w}$ potrawach $\mathrm{z}$ roślin strączkowych [17]. Młode liście wraz z pędami mogą być dodatkiem do sałat, surówek, zup oraz 
sosów [18]. Przyprawa jest najczęściej używana w kuchni francuskiej, hiszpańskiej oraz włoskiej [19].

W medycynie tymianek jest uznawana za roślinę „dobrą dla ducha”, ponieważ działa uspokajająco. Wpływa na poprawę pracy układu pokarmowego, dlatego często włącza się go do diet dla osób z problemami żołądkowymi, dolegliwościami wątrobowymi, czy podrażnionymi jelitami [20]. Napar z tymianku jest stosowany przy uporczywych biegunkach. Wspiera prawidłową perystaltykę jelit, stąd dodawany do dań ciężkostrawnych. Tymianek wykorzystuje się również jako główny składnik syropów na kaszel (tymianek ma działanie rozkurczowe) [21]. Dodatkowo służy jako środek przeciwbakteryjny, więc dobrze sprawdza się w przypadku infekcji gardła lub stanów zapalnych jamy ustnej [22]. Tymianek wykazuje również właściwości antyoksydacyjne, jest to powiązane $\mathrm{z}$ dużą zawartością polifenoli w roślinie [23].

W kosmetyce tymianek wykazując działanie łagodzące zajmuje jedno z głównych miejsc na listach składników maści, kremów, szczególnie polecanych dla osób o cerze wrażliwej. Jest on stosowany przy produkcji BIO-past do zębów, też z dodatkiem aloesu i anyżu [24]. Zioło to jest również składnikiem mydeł oraz mieszanek ziołowych do kąpieli [25].

Ziele tymianku, używane jest także w celach dekoracyjnych, przy tworzeniu bukietów ziołowych czy saszetek zapachowych a świeże bądź susze rośliny działają odstraszająco na owady [26].

Obecnie wiele badań koncentruje się na możliwości zastosowania olejków i ekstraktów z tymianku jako substancji wpływających hamująco na procesy degradacyjne produktów spożywczych i kosmetyków [2, 27]. Kozłowska i Ścibisz (2012) badając antyoksydacyjne właściwości ekstraktów różnych ziół oceniły, iż ekstrakt z tymianku charakteryzował się najwyższą zawartością polifenoli [23]. Badania Zaborowskiej i wsp. (2011) wykazały, 
że ekstrakty tymianku skutecznie limitowały zmiany oksydacyjne oleju słonecznikowego [28]. Adaszyńska i Swarcewicz (2012) w swojej pracy podkreślają potencjał możliwości wykorzystania tymianku (olejek, ekstrakt) w kosmetykach jako naturalnego antyoksydantu [29].

\section{Właściwości prozdrowotne}

Biologicznie czynne substancje zapachowe pochodzące z olejków eterycznych tymianku mają szerokie zastosowanie w aromaterapii. Dzięki inhalacjom bądź podawaniu na skórę (masaże, kąpiele lub kompresy) mogą wspierać terapie antybiotykowe [30].

$\mathrm{Z}$ ziela tymianku pospolitego pozyskuje się do 2,6\% olejku eterycznego, w tym: tymol (do 45\%), karwakol (25-60\%), borneol (85\%), p-cymen (7-20\%), beta-kariofilen (1-3\%), linalol (ok.8\%). Ekstrakty z tymianku są składnikami licznych tabletek do ssania, kropli, syropów wykrztuśnych i przeciwkaszlowych. Tymol dzięki tym właściwościom skutecznie usprawnia pracę rzęsek oskrzeli, co jest przydatne przy infekcjach bakteryjnych gardła. Bardzo ważnymi i użytecznymi składnikami czynnymi tymianku obok olejku eterycznego (3,5\%-5,4\% zawartości) są kwasy fenolowe (kwas kawowy, chlorogenowy, kwasy rozmarynowe), triterpeny (kwas oleanolowy, ursolowy), garbniki (zawiera ich ok $10 \%$ ) oraz flawonoidy, które nadają roślinie właściwości żółciopędnych, przeciwzapalnych, hepatoprotekcyjnych i moczopędnych. Tymol i karwakol po podaniu doustnym stymulują system tkanki limfatycznej układu pokarmowego, pobudzają w nim krążenie krwi oraz generują nabłonek. Fenole i flawonoidy mają działanie rozkurczowe a co ważniejsze - ograniczają powstawanie toksycznych amin biogennych w jelicie grubym $[17,31]$.

Poza tym tymianek zawiera witaminy $\mathrm{z}$ grupy $\mathrm{B}$ (głównie ryboflawinę) wpływające pozytywnie na układ nerwowy oraz 
witaminę A, C, E i K. Tymianek oprócz witamin posiada również kompleks składników mineralnych takich jak mangan, selen, żelazo, wapń, potas czy magnez. Mangan wraz $\mathrm{z}$ magnezem są odpowiedzialne za prawidłową pracę układu mięśniowego i nerwowego, a dodatkowo hamują krzepnięcie krwi. Selen wspomaga układ odpornościowy oraz normuje pracę tarczycy. Wapń wzmacnia kości oraz zęby, zaś potas zachowuje równowagi kwasowo-zasadowej organizmu $[6,32]$.

\section{Podsumowanie}

Tymianek jest cenioną rośliną, powszechnie uprawianą w Polsce. Jej walory smakowe, lecznicze jak i ozdobne są szeroko cenione. Obecny kierunek rozwoju branży spożywczej i kosmetycznej koncentruje się na opracowywaniu produktów chrakteryzujących się najprostszym składem (przy zachowaniu pożądanego smaku/zapachu i naturalnie bezpieczeństwa produktu). To powoduje zwrócenie się producentów żywności, jak i kosmetyków w stronę intensywniejszego wykorzystania ziół. Obecnie trwają badania nad możliwością zastosowania tymianku w produkcji spożywczej (stabilizatory), jak i kosmetycznej (antyoksydanty).

\section{Bibliografia/Bibliography:}

1. Kawałko M.J. Historie ziołowe. Krajowa Agencja Wydawnicza, Lublin 1986.

2. Dudek-Makuch, M., Knoska, K., Chanaj-Kaczmarek, J. Naturalne przedłużanie trwałości produktów spożywczych. Post Fitoter 2019;20(3):208-215. 
3. Skotnicka M., Golan M., Szmukała N. Rola naturalnych przeciwutleniaczy pochodzenia roślinnego w profilaktyce nowotworowej. Ann. Acad. Med. Gedan. 2017; 47:119-127.

4. Kalemba-Drożdż M., Witamina $\mathrm{C}$ w leczeniu nowotworów i profilaktyce chorób niezakaźnych. Oficyna Wydawnicza KA AFM. Retrieved April 16 2020, from:

https://www.ceeol.com/search/article-detail?id=738303.

5. Kędzia A., Dera-Tomaszewska B., Ziółkowska-Klinkosz M., Kędzia A.W., Kochańska B., Gębska A. Aktywność olejku tymiankowego (Oleum Thymi) wobec bakterii tlenowych .Postępy Fitoterapii 2012;2:7-71.

6. Tymianek. Artykuł popularno- Naukowy, Retrieved April 16, 2020, from: https://natur- sklep.pl/kategoria/index/tymianek/.

7. Sieroń R. Uprawa ziół - dobry pomysł na biznes. Retrieved April 16, 2020, from: https://www.sodr.pl/swietokrzyski-portalrolny/aktualnosci/Uprawa-ziol-dobry-pomysl-na-biznes/idn:543\#top.

8. Kostyra M., Albera-Łojek A., Łojek J. Zioła w terapii i profilaktyce schorzeń u koni. Wiadomości Zootechniczne, 2018;(56),1:90-107.

9. Mazik M. Tymianek - uprawa w ogródku ziołowym. Jak uprawiać tymianek i jak zbierać ziele tymianku, Retrieved April 16, 2020, from: https://muratordom.pl/ogrod/rosliny/tymianek-uprawa-w-ogrodkuziolowym-jak-uprawiac-tymianek-i-jak-zbierac-ziele-tymianku-aay1vU-2jtx-Gz9M.html.

10. Sadowski A. Uprawa ziół i możliwość ich wykorzystania, Uniwersytet w Białymstoku, Białystok 2013, Retrieved April 16, 2020, from: http://podlaskie.ksow.pl/fileadmin/user_upload/ podlaskie/pliki/publikacje_2012/Publikacje_2013/uprawa_ziol_23-112013.pdf. 
11. Pitek J. Tymianek właściwy (Thymus vulgaris L.). Retrieved April 16, 2020

from: http://www.blog.ziolowo.pl/2013/04/06/tymianek-wlasciwythymus-vulgaris-l/.

12. Król B., Kiełtyka-Dadasiewicz A. Wpływ metody suszenia na cechy sensoryczne oraz skład olejku eterycznego tymianku właściwego (Thymus vulgarius L.), Żywność. Nauka. Technologia. Jakość. 2015;4(101):162-175.

13. Tys J., Sujak A., Rybacki R. Wpływ temperatury suszenia na zawartość barwników w nasionach rzepaku ozimego. Rośliny Oleiste, 2002;(23):95-102.

14. Radziewicz J. Tymianek - w kuchni i medycynie. Rolniczy magazyn elektroniczny. Retrieved April 16, 2020, from: https://rme.cbr.net.pl/index.php/archiwum-rme/545-rolniczymagazyn-elektronicynz-marzec-kwiecie-nr-66/zioowy-zaktek2/736tymianek-w-kuchni-i-medycynie.

15. Wielądko W. Kucharz doskonały. Muzeum Pałac w Wilanowie, 2012.

16. Gumowska I. Ziółka i my. PTTK „Kraj” 1983.

17. Skarżyński A. Zioła czynią cuda. Agencja Wydawnicza COMES, Warszawa 1994.

18. Kałużny K., Koźmińska A. Zagadnienia aktualnie poruszane przez młodych naukowców 2, Tom 1, Rodzaj macierzanka (Thymus) w przestrzeni miejskiej, CREATIVETIME, Kraków 2015:94-97.

19. Bogucki G. Macierzanka tymianek. Retrieved April 16, 2020, from: https://budujesz.info/artykul/macierzanka-tymianek--tymianekpospolity-tymianek-wlasciwy-macierzanka-zwyczajna,199.html. 
20. William A. Medical medium: secrets behind chronic and mystery illness and how to finally heal. Hay House Uk Ltd., 2015.

21. Grochowska U. Poradnik żywieniowy dla chorych na chorobę Leśniowskiego-Crohna lub wrzodziejące zapalenie jelita grubego, Towarzystwo „J-elita”, Warszawa 2016

Retrieved April 16, 2020, from: https://j-elita.org.pl/wpcontent/uploads/2016/07/poradnik-zywieniowy-2016.pdf.

22. Nowak G., Nawrot J. Surowce roślinne i związki naturalne stosowane w chorobach układu oddechowego. Herba Polonica, 2009;55(4):178-213.

23. Kozłowska M., Ścibisz I., Badanie zawartości polifenoli i aktywności przeciwutleniającej ekstraktów z roślin przyprawowych podczas ich przechowywania, Bromat. Chem. Toksykol. 2012;(45),3:358-363.

24. Ożarowski A., Jaroniewski W., Rośliny lecznicze i ich praktyczne zastosowanie, Instytut Wydawniczy Związków Zawodowych, Instytut Wydawniczy Związków Zawodowych, Warszawa 1987. Retrieved April 16, 2020,

from: https://www.poradnikzdrowie.pl/zdrowie/apteczka /tymianek-wlasciwosci-prozdrowotne-tymianku-aa-ha1d-GBKhke3S.html\#tymianek-zastosowanie-w-kosmetyce.

25. Wierucka-Rybak M. Kosmetyczne i lecznicze mieszanki ziołowe do kąpieli, Retrieved April 16, 2020

from: https://www.doz.pl/czytelnia/a12060-Ziola_do_kapieli__jak_dzialaja.

26. Przyprawowy, Zioła odstraszające komary, muchy i inne owady. Retrieved April 16, 2020,

from: http://www.przyprawowy.pl/historia-przypraw/14artykul/164-ziola-odstrzaszajace-komary-muchy-i-inne-owady.html. 
27. Adaszyńska, M. Swarcewicz, M. Olejki eteryczne jako substancje aktywne lub konserwanty w kosmetykach. Wiadomości Chemiczne 2012:139-158.

28. Zaborowska Z., Przygoński K., Dziarska B., Wojtowicz E., Kupka, A. Wpływ ekstraktów tymianku i rozmarynu na stabilność oksydatywną oleju słonecznikowego. Bromat. Chem. Toksykol. 2011;(44),3:877-882.

29. Adaszyńska M., Swarcewicz M., Olejki eteryczne jako substancje aktywne lub konserwanty w kosmetykach, Wiadomości chemiczne, 2012;66:1-2.

30. Zdrojewicz Z., Minczakowska K., Klepacki K. Rola aromaterapii w medycynie., Family Medicine \& Primary Care Review 2014;16,4: 387391.

31. Kazimierczak R., Przyprawy ziołowe, Warszawa 2017, Retrieved April 16,2020 ,

from: http://www.wszechnica-zywieniowa.sggw.pl/

Prezentacje/2017/Slajdy1_marzec_2017.pdf

32. Pawłowski A., Szeląg D. Wygraj zdrowie z naturą. PWH Arti, Ożarów Mazowiecki 2019:288-290. 